\title{
The Ultrasound-accelerated Synthesis of New 7-
} Aminocarbohydrate-isoquinoline-5,8-quinone Derivatives

\section{Wanderson Amaral da Silva ${ }^{a}$, Vinícius Rangel Campos ${ }^{a}$, Angela Cristina P. B. dos Santos $^{a}$, Alessandro K. Jordão ${ }^{a}$,Vitor F. Ferreira ${ }^{a}$, Maria Cecília B. V. de Souza ${ }^{a}$ and Anna Claudia Cunha* \\ ${ }^{a}$ Universidade Federal Fluminense, Departamento de Química Orgânica, Outeiro de São João Batista, s/nº, Niterói, 24120-050, Rio de Janeiro, Brazil.}

*corresponding author. Tel.: +55 21 26292364; Fax: +55 21 26292135; e-mail: annac@vm.uff.br Keywords: aminocarbohydrates, isoquinoline-5,8-quinone and ultrasound

\section{INTRODUCTION}

The synthesis of aminoquinones and related compounds has attracted considerable attention, because they exhibit a wide spectrum of pharmaceutical activities including antitumor and antimalarial properties ${ }^{1}$. Two general methods are available for the synthesis of aminoquinones²: nucleophilic substitution reaction of halo-derivative quinones with amines and direct 1,4-type addition of amines to quinones, with or without Lewis acid conditions under ultrasonic irradiation. As part of an ongoing research program on the synthesis of new quinone derivatives and on the basis of our experience in the field of the use of carbohydrates in organic synthesis, we herein report an extension of the second approach ${ }^{3}$ which led to three novel isoquinoline-5,8-quinone derivatives 1a-c, possessing a carbohydrate chain at C-7position of the quinone ring.

\section{RESULTS AND DISCUSSION}

The isoquinolinequinone 2 prepared in a $80 \%$ yield by the method of Valderrama and coworkers ${ }^{4}$, was submitted to addition reaction with different aminocarbohydrates 3a-c, giving the corresponding 7-substituted amino-isoquinoline-5,8-quinone derivatives 1a-c, in good yields. The aminocarbohydrates $^{5}$ were easily obtained from commercially reagents such as D-ribose, D-xylose and D-galactose.

The compounds 1a-c were purified by column chromatography on silica gel and their structures structures were fully characterized by $I R$ and ${ }^{1} \mathrm{H}$ NMR spectroscopies.

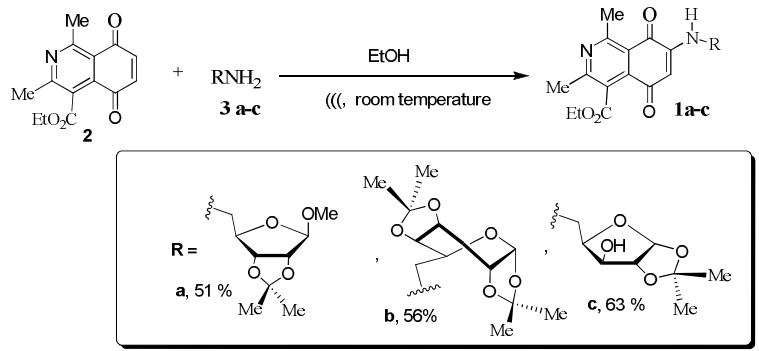

Scheme 1. Synthesis of 7-substitutedaminonaphthoquinones 1a-c.

\section{CONCLUSION}

In conclusion, we have developed the synthesis of a new series of 7-substituted-aminoquinone derivatives by reaction of isoquinolinequinone 2 with different aminocarbohydrates 3a-c.

\section{ACKNOWLEDGEMENTS}

This work was supported by the Brazilian agency FAPERJ-Pronex. Fellowship granted to UFF, by FAPERJ, Capes, CNPq-PIBIC is gratefully acknowledged.

\section{REFERENCES}

${ }^{1}$ Franco, C. F. J.; Jordão, A. K.; Ferreira, V. F.; Pinto, A. C.; Souza, M. C. B. V.; Cunha, A. C. J. Braz. Chem. Soc., 2011, 22, 1, 187-193.

${ }^{2}$ Liu, B.; Ji, S. J., Synt. Commun., 2008, 38, 1201.

${ }^{3}$ Santos, F. C. ; Abreu, P.; Castro, H. C.; Cirne-Santos, C. C.; Giongo, V.; Barbosa, J. E.; V. ; Bou-Habib, D. C.; Silva, D. O.; Temerozo, J. R.; de

Souza, T. M.; Cunha, A. C.; Rodrigues, C. R.; Ferreira, V. F.;

Souza, M. C. B. V., Bioorg. Med. Chem. 2009, 17, 5476. 
4 Valderrama, J. A.; lbacache, J. A.; Arancibia, V.; Rodriguez,

J.;Theoduloz, C., Bioor. Med. Chem., 2009, 17, 2894-2901.

Cunha, A. C. Pereira, L. O. R. ; Souza, R. O. P. ; Souza, M. C. B. V.

Ferreira, V. F., Nucleosides, Nucleotides Nucleic Acids, 2001, 20, 1555. 